\title{
AsSESSING THE IMPACT OF ARTISTIC ARCHITECTURE ON Perceived Usability AND WiLlingness To Use MobILE COMMERCE APPLICATIONS
}

\author{
Tola John Odule ${ }^{1}$ \\ ${ }^{1}$ Department of Mathematical Sciences \\ Olabisi Onabanjo University, Ago-Iwoye \\ P.M.B. 2002, Ago-Iwoye, Ogun State, Nigeria \\ tola.odule@oouagoiwoye.edu.ng1
}

\begin{abstract}
Creating a useful portable browser or program is a demanding challenge for organisations due to the size constraints of the display area, which additionally is contingent on usability, internet connectivity, efficient backup power and mobility. Users also expect performance equivalent to that of microcomputers. Portable display programmers need to surmount these challenges without compromising users' concerns for safety and confidentiality. Various works in the past couple of years revealed the ability of a strongly perceived artistic architecture of a mobile website as a push to overcome clients' reduced usability skill. The investigation conducted in this report sought to determine the distinct impact of eight artistic display attributes on the perceived usability of a mobile website or program and the corresponding clients' willingness to use. Organisations may thus take advantage of this knowledge to improve usage, trust, frequency of adoption and consequently financial rewards on mcommerce applications. This study uses a fractional factorial design with a screening objective. Data for the experiment was sourced through a web-based questionnaire program, Qualtrics. At the same time, social network sites were used to disseminate the questionnaires to enable gathering a good number of respondents. The data collection instrument had 42 statements with a $10 \%$ threshold for missing values Ninety-six (96) participants took part in the inquiry. In contrast, seventy-six (76) participants completed the exercise, signifying an estimated $21 \%$ drop - out. Multiple regression analysis was used in the study of the association concerning the dependent and independent variable(s). SPSS package was utilised in the evaluation of the multiple regression analysis. Findings revealed that artistic architecture bears a substantial impact on perceived usability of portable websites and programs as well as influences willingness to use artefacts on such platforms. Screen density, as well as the colour design of an application, turned out as two features with the highest impact on the two dependent factors. That the orientation of their effects is a reverse of the conjectured outcome suggests that future work should explore this issue.
\end{abstract}

Keywords - M-commerce, artistic architecture, mobile display attributes, m-commerce application

\author{
Ademola Olusola Adesina ${ }^{2}$ \\ ${ }^{2}$ Department of Mathematical Sciences \\ Olabisi Onabanjo University, Ago-Iwoye \\ P.M.B. 2002, Ago-Iwoye, Ogun State, Nigeria \\ ademola.adesina@oouagoiwoye.edu.ng2
}

\section{INTRODUCTION}

Mobile commerce ( $m$-commerce $)$ is a quickly developing means of promoting a large share of worldwide retail deals. M-commerce is described as a bi-directional or multi-directional communicational and advertising exercise between an organisation and its clients, utilising a cell phone, web-based channel or innovation [1]. Going by Statista record [2], the population of global cell phone clients is conjectured at close to 3.5 billion around 2020. By 2019, this population was well over 2.6 billion clients around the world. Close to that, the population of clients with tablets got to 1.2 billion as at 2016 and around 1.5 billion as at 2018 [3]; thereby affirming the presence of computer age.

Nevertheless, m-commerce is quite a novel means having factors which fundamentally are not quite the same with the traditional ways. While e- commerce was widely examined in previous years, relatively few investigations were recorded in the area of m-commerce. A worldwide study conducted by Criteo [4] revealed that European nations are experiencing difficulty accomplishing satisfactory adoption levels in the cell phone retail business. Discoveries from [5] propose that ease of use, security, protection and innovative challenges impede individuals from embracing m-commerce. An earlier empirical investigation in this area hitherto brought to the fore these numerous challenges being potential hindrances in the implementation of this novel innovation $[6 ; 7]$.

Considering the discoveries in [5], it is seen that a number of the major concerns bordered on the convenience of use (usability) associated with the program or the portable browser. Since cell phone displays are considerably lesser in size compared to those of laptops, it beholds that the ease of use of cell phone screens is comparatively low concerning such gadgets. Previously, a massive investigation had gone into assessing the ease of use of websites as well as its adequacy in e-commerce. Presently, the e-commerce business is in its developed states just as series of scientific exploration in the creation of application screens have enriched the appropriateness of websites, significantly because of the increase in their ease of use [8]. Will enhanced screen planning result in corresponding enhanced acceptance as well 
as the efficiency of mobile commerce? This question indeed calls for a fascinating, incisive investigation.

The artistic architecture of websites and programs is an area which has attracted considerable interest in the previous years. Artistic architecture is described as a complete affective presentation of a portable website or application, rendered via colours shapes, font types, music, or animation [9]. In the view of contemporary investigations, an artistic architecture may fundamentally impact perceived usability (PU) , perceived ease-of-use (PEOU), loyalty , trust, including similar affective feelings $[10 ; 11 ; 12 ; 13]$. Such results may influence higher acceptance rate as well as the efficiency of m-commerce.

The prospect of creating a useful portable browser or program has been a demanding challenge for organisations. Users expect equivalent performance with that offered by microcomputers which must be fitted within a significantly lesser display. Additionally, this display is contingent on usability, internet connectivity, backup power longevity, as well as mobility. Similarly, the design should accommodate concerns of users with fears in loss of confidentiality and safety in the utilisation of portable gadgets. Portable display programmers need to surmount challenges posed by enhancing the mobile display within the constraints of size without compromising users' concerns. Providing functionalities equivalent to that of e-commerce in efficiency by portable browsers or programs is herculean for the majority of organisations. Comprehending clients' behavioural attitudes is vital in a mobile business setting, and this understanding should reflect in the architecture of the portable display. Some factors are known to affect the real convenience of use and involvement. Consequently, such factors should be evaluated and ascertained to know the best enhanced artistic architecture of portable websites and programs. Organisations may thus take advantage of this knowledge to improve the design of portable displays, thereby improving usage, trust, frequency of adoption and consequently financial rewards on m-commerce operations.

Previous investigations examined the impact of artistic architecture on different aspects of affective influence, very notably impact on perceived usability (PU). $[14 ; 15 ; 16 ; 17$; 18]. While the authors give clarification concerning classical and expressive aesthetics, no previous work exists where the impact of different distinct factors of design aesthetics is jointly investigated. However, authors exist whose work investigated the impact of distinct individual factors, e.g., the impact of symmetry $[19 ; 20]$. Unfortunately, the authors evaluate just a single factor. This work does a joint evaluation of the different factors to show the impact of individual factors as a way of creating an aesthetically-optimised customer display, as well as proffer suggestions regarding such enhancements. This observation is a missing link in empirical studies on m-commerce that this work fills and thus, its contribution. Standards in the artistic architecture of a portable display may be the starting point in achieving general as well as reliable procedures for portable gadgets architects which will consider all aspect of client display architecture.

The focus of this paper is an exposition on artistic architecture in the m-commerce setting together with its impact on users' affective feelings.

The remainder of this report is organized as follows. Section 2 reviews the relevant literature, proposes the hypotheses and the underlying conceptual framework. Section 3 introduces the materials and methods used for the study. Results, testing of the regression models and the hypotheses developed, including discussion of results dominate section 4 . Section 5 concludes the report, presents key implications of the study, identifies the study's limitations and suggests areas for further research.

\section{RELATED WORKS}

\section{A. Artistic Architecture}

The artistic architecture was independently discovered to have a fundamental influence on perceived usability $(P U)$ and perceived ease-of-use (PEOU) $[15 ; 16 ; 21 ; 17$; 18]. Likewise, a few of the works discovered that PU, as well as PEOU, has a notable influence on a client's devotion [14], and confidence [21]. An immediate major effect of artistic architecture on clients' trust concerning m-commerce was reported by [21]. References $[15 ; 16]$ in two separate investigations found a framing effect whereby client's view of artistic beauty and total disposition changed in response to the challenge. The Studies submitted that this was due to a halo effect, meaning esteem perceived artistic interest in a website may counteract clients' inexperience with usage. A comparable framing effect was reported by [22], implying circumstance being a critical variable impacting resistance of clients' views: clients are susceptible to modifying choice given the situation.

Investigations showed artistic architecture to impact clients' affective state fundamentally. Reference [17] discovered common affective impact while different studies found major effects on certain affective states, such as genderbased affective feelings [23] and expected internet-based service quality [24]. A major influence of website architecture on clients' perceived trust and satisfaction that invariably result in esteemed devotion of the client was discovered by [25]. Meanwhile, discoveries from these investigations allude this outcome to be probably impacted by the client's societal values since, in a few conventions, only some of the impacts count.

A different impact noticed in works on artistry is the impact on the improvement of graphical architecture and artistry concerning the relevance of the conceptual structure [26]. This impact explains a conceptual structure whereby clients favour one having better artistry over a conceptual structure having reduced artistry, given identical structure in the two scenarios. 
B. Measurement Models: Mobile Display Attributes

According to [27], clients' view of artistry is twodimensional: classical artistry and communicative artistry. The former is characterised by plain, systematic as well as unambiguous, motivated by factors congenital to client's usability considerations. At the same time, the second is reflective of the architect's artistry, novelty and communicative capability, which ideally improves the client's emotional usability, thus arousing affective appeal. This conceptual representation of [27] was applied by [28] as a foundation for the suggestion of Visual Aesthetics of Website Inventory (VisAWI) frame work which established four associated aspects of perceived graphical artistry: Simplicity, Diversity, Colourfulness and Craftsmanship. The empirical investigation reported in this work utilises the aggregated discoveries of the two conceptual frameworks as its foundation, whereby impacts of the classical and communicative artistry are evaluated. Factors employed in the investigation are intimately connected with factors utilised by the classical-communicative as well as the VisAWI frameworks.

\section{Conceptual Framework and Hypotheses}

The impact of artistic architecture jointly on perceived usability and willingness to use are investigated in this work. A graphical representation of the proposed model appears in Fig. 1 below.

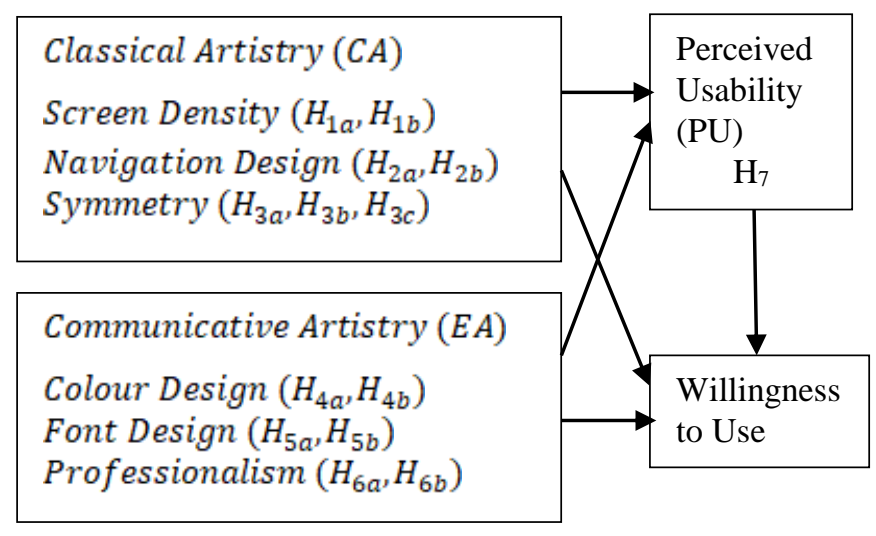

Fig. 1: The Conceptual Framework

\section{Classical Artistry}

This study examined the impact of screen density, the totality of products featured on a display, as a specific feature of $\mathrm{CA}$, on perceived usefulness and willingness to use. It is assumed that showing a smaller number of goods on a display (low screen density) affords bigger pictures of the products rendered in contrast to high screen density. Reference [29] posits that bigger images may result in a substantially higher rate of transformation. While the assertion was verified for e-commerce it is yet to be established for $\mathrm{m}$ commerce. The hypothesis, therefore, is low screen density, results in greater willingness to use.
$H_{1 a}$ : Interface designs with low screen density will lead to higher perceived usability

$H_{1 b}$ : Interface designs with low screen density will lead to a higher willingness to use

A different CA feature investigated is the impact of navigation design on perceived usability and willingness to use. It was discovered that just the connecting configuration architecture of websites results in a major effect on clients' affective appeal and willingness to use. In contrast, no major associations exist for menu plan [30]. A combination of menu options, as well as connecting options, is investigated in this report. It is anticipated that notable dissimilarity in navigation design of portable display results in higher perceived usability and willingness to use.

$\mathrm{H}_{2 a}$ : Clear and simple navigation design positively affects perceived usability.

$H_{2 b}$ : Clear and simple navigation design positively affects willingness to buy

One other CA feature investigated is the impact of symmetry on perceived usability and willingness to use. It is conjectured that willingness to use is fundamentally impacted by perceived usability [31; 32]. Thus the hypothesis is symmetry positively impacts clients' willingness to use.

$H_{3 a}$ : Symmetry positively affects users' perceived usability $H_{3 b}$ : Symmetry positively affects users' willingness to use

$H_{3 c}$ : Artistic perceptions of males on symmetry are significantly different from females

\section{E. Communicative/Expressive Artistry (EA)}

A feature of EA investigated in this work is the effect of colour design on perceived usability and willingness to use. Discoveries concerning the appropriate colour that is optimal for merchandise setting are diverse. A possible reason for such contradictory results may be traceable to cultural variations. Nevertheless, this work evaluates blue shades alongside neutral (i.e., black, white and grey) shades to determine whether the application of colours impact perceived usability and willingness to use.

$H_{4 a}$ : The use of extreme short-wavelength colours positively influences perceived usability

$H_{4 b}$ : The use of extreme short-wavelength colours positively influences the willingness to use

The next EA feature examined is the impact of font design on perceived usability and willingness to use. Font architecture was considered to be a component of graphical architectural artistry of a website [24]. Nevertheless, the impact of font architecture on these affective appeals is yet to be ascertained individually; but the better selection in font architecture may improve clients' view regarding graphical artistry, in consonance with the Diversity feature in the VisAWI conceptual representation [27]. Likewise, [33] posited that font size positively impacts both 
ease-of-use and clients' artistic inclination, suggesting a preference for larger fonts.

$H_{5 a}$ : Variety in font design positively affects perceived usability

$H_{5 b}$ : Variety in font design positively affects willingness to use A final feature of EA investigated is the impact of Professionalism on a portable browser or program on perceived usability and willingness to use. Two divergent views of this factor are taken for this purpose. First, is a site that appears skilfully, deftly planned to have a comparatively extraordinary use of streaks to divide wares and navigation buttons with an application of quite suggestive images. Alternatively, the architecture is intuitive and explorative, having a comparatively little application of streaks and quadrangular forms while utilising additional imaginative images. An extra creative and unique architecture is considered by clients to be more graphically artistic, given the conceptual representations of [27] and [28].

$H_{6 a}$ : Professional appearance negatively affects perceived usefulness

$H_{6 b}$ : Professional appearance positively affects willingness to use

Lastly, while there are distinct factors that impact on willingness to use, it is instructive to investigate the intervening impact of perceived usability. Going by empirical findings, greater supposed usability presumably results in greater willingness to use.

$H_{7}$ : Perceived usability positively influences the willingness to use

\section{MATERIALS AND METHODS}

\section{A. Research Design}

This study uses a fractional factorial design with a screening objective that facilitates determining the impact of the distinct variable via the application of a limited amount of trials (i.e., 16 trials). The investigation was structured and well composed with variables independently structured. Table 1 presents the total $1 / 16^{\text {th }}$ fractional factorial design, together with the tags of the two-level variables. The subjective responses in this study were examined by an online distributed survey. The 16 screenshots utilised in the study were predicated on actual screenshots through the application of prevailing artefacts. They were about equal dimension to a typical cell phone display to enhance the experiment's external validity. As a way of strengthening the internal validity of the investigation, the 16 screens were randomly offered to the population survey as a way to circumvent anchoring effects. Similarly, some mediating factors were included in the study to check for potential confusing impact.

TABLE 1

STRUCTURE OF INVESTIGATION: MANAGEMENT OF DISPLAY ATTRIBUTES

\begin{tabular}{|c|c|c|c|c|c|c|c|c|}
\hline Screen & $\begin{array}{l}\text { Screen } \\
\text { Density }\end{array}$ & $\begin{array}{l}\text { Navigatic } \\
\text { Design }\end{array}$ & n Symmetry & $\begin{array}{l}\text { Colour } \\
\text { Design }\end{array}$ & $\begin{array}{l}\text { Font } \\
\text { Design }\end{array}$ & $\begin{array}{l}\text { Profession } \\
\text { alism }\end{array}$ & $\begin{array}{l}\text { Product } \\
\text { Rating }\end{array}$ & $\begin{array}{l}\text { Reference } \\
\text { Price }\end{array}$ \\
\hline 1 & High & $d$ & al & & ty & Profe: & tings & No Re \\
\hline 2 & Low & $A d v c$ & Asymmetrical & Neutral & Variety & Professional & Ratings & No RefPri \\
\hline 3 & Low & Simple & Asymmetrical & Neutral & No Variety & Playful & No Ratings & No RefPri \\
\hline 4 & Low & Simp & Symmetrical & Cool & Variety & Playful & Ratings & No $F$ \\
\hline 5 & Low & Simple & Symmetrical & Cool & No Variety & Professional & Ratings & RefPrice \\
\hline 6 & High & Advanced & Symmetrical & Neutral & No Variety & Profes. & igs & No RefPric \\
\hline 7 & Low & Simple & Asymmetrical & Neutral & Variety & Professional & atings & RefPrice \\
\hline 8 & High & Simple & Symmetrical & Neutral & Variety & Playful & No Ratings & No RefPri \\
\hline 9 & High & Simple & Asymmetrical & Cool & Variety & Professional & Ratings & RefPrice \\
\hline 10 & Low & Advanced & Symmetrical & Cool & Variety & Playful & No Ratings & RefPrice \\
\hline 11 & Low & Advanced & Symmetrical & Cool & No Variety & Professional & No Ratings & No RefPri \\
\hline 12 & High & Simple & Symmetrical & Neutral & No Variety & Professional & No Ratings & RefPrice \\
\hline 13 & Low & $A d v$ & Asy & Neutral & No Variety & Playful & Ratings & RefPrice \\
\hline 14 & High & $\operatorname{Adn}$ & $A s]$ & Cool & No Variety & Playful & No Ratings & RefPrice \\
\hline 15 & High & Sim & As] & Cool & No Variety & Playful & $R a$ & fPri \\
\hline 16 & High & Advanced & Symmetrical & Neutral & Variety & Playful & Ratings & RefPrice \\
\hline
\end{tabular}


B. Measures and Manipulations

The population survey was asked to rank 16 distinct screenshots for usability and willingness to use to ascertain the influence of artistic architecture on perceived usability and willingness to use. The architecture of these displays had a mixture of eight autonomous factors, with each screen having a unique mix of features.

Autonomous Factors and Management

1. Screen Density: This feature may read Low $=0$ or High $=1$. Two products are shown on the screen if the density is 0 . Symmetric displays that read 1 feature four wares while asymmetric displays that read 1 hold three wares. This implies the difficulty of adding four wares on an asymmetric screen while still maintaining readability.

2. Navigation Design: This variable may be Simple $=0$ having an options tab and a find tab located on the upper part of the display as well as a scroll tab beneath the display. Displays whose navigation design is advanced (1) have one additional find tab and another tab that offers choices for specifying constraints.

3. Symmetry: This variable is rated as Asymmetrical $=0$ or Symmetrical $=1$, indicating if the wares are proportionately balanced in terms of arrangement on the display or otherwise.

4. Colour Design: This variable is classified as Neutral $=0$ or Cool $=1$. Light grey is utilised in displays having neutral architecture while blue is the choice for displays having cool colour architecture. Variations in colour manifest behind the scene (e.g., scroll tabs) including the images.

5. Font Design: This feature is rated as No Variety $=0$ consisting of the same size, black font. Variety $=1$ contains a font with differences in size and colour, and the font type will be bold.

6. Professionalism: indicates the extent to which the architecture of the display reflects an expert look. The value $P$ layful $=0$ means the architecture appears skilfully deftly planned, having a comparatively extraordinary use of streaks to divide wares and navigation buttons with the application of quite suggestive images. Professional $=1$ implies the architecture is intuitive and explorative, having a comparatively little application of streaks and quadrangular forms while utilising additional imaginative images.

7. Product Rating: This variable is classified as No Product Rating $=0$ or Product Rating $=1$. The wares were rated equally as 4.5 where displays include rankings for wares to circumvent inclinations occasioned by a ranking of wares.

8. Reference Price: This feature is rated as No Reference Price $=0$ or Reference Price $=1$. Operational control concerning this variable is direct.

\section{Evaluation of Related Factors}

The two related factors: perceived usability and willingness to use were examined in this work according to the feedback of the population study. Reference [34] demonstrated univariate rules as consistent evaluation approach to ascertain attitude and affective feelings like career fulfilment disposition regarding commercials or products. As perceived usability and willingness to use may be described as an affective appeal concerning display architecture, it suffices that a univariate evaluation rule is adequate to summarise participants feedback. In the questionnaire, the two related factors were evaluated by propositions. Participants were asked to rate the individual 16 screens, on a $0-100$ weight, where 0 denotes complete dissent, and 100 denotes full assent.

\section{Analysis of Experiment \\ Design of Survey Instrument}

The data used for this experiment was sourced via a webbased inquiry generated through a web-based questionnaire program, Qualtrics. Social network sites were used to disseminate the questionnaires through an unnamed open connection to enable gathering a good number of respondents.

The demography of sample participants consists of lowincome literates within the 18-25 age range. To enhance the validity and reliability of the questionnaire [35], three experts in the field of study initially reviewed the data collection instrument and the sampling method. A trial investigation with the instrument was subsequently conducted using 11 participants. Refinement of the instrument was done using recommendations of respondents in the trial study concerning the organisation, precision of expression, as well as relevance [36].

Ninety-six (96) participants took part in the inquiry while seventy-six (76) participants completed the exercise, signifying an estimated $21 \%$ drop-out. Most of these drop-outs were recorded at the start of the second section, where participants were required to rank the 16 screens on usability and willingness to use. No missing values were recorded for any question in two of the uncompleted questionnaires while the other 78 questionnaires were checked for missing values. The data collection instrument had 42 statements in all with a $10 \%$ threshold for missing values, indicating the acceptability of 4 maximum missing values. 


\section{Vol. [46], Issue [1], Year (2020)}

\section{Evaluation of Field Results}

Having recoded and tidied the field results, a record of 77 participants remained. Some of the key characteristics of the demographic and behavioural attributes of the participants in the sample are summarized in Fig. 2.

A. Gender

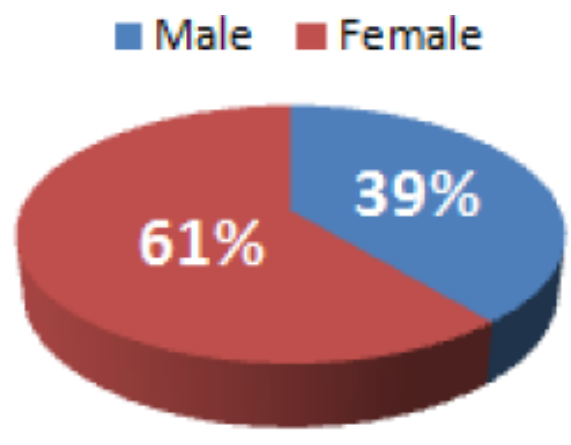

B. Food Processor Ownership

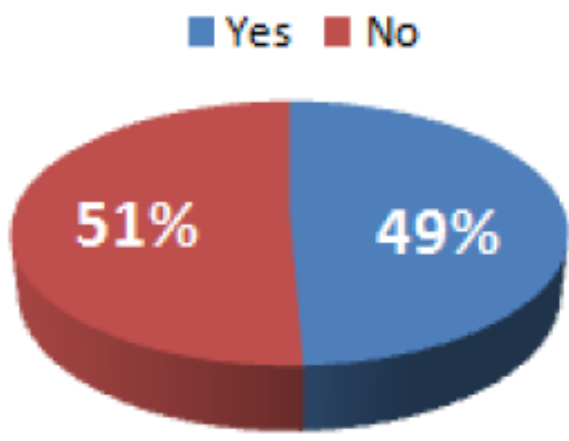

C. Interest in Using Food Processor

\section{Yes No}

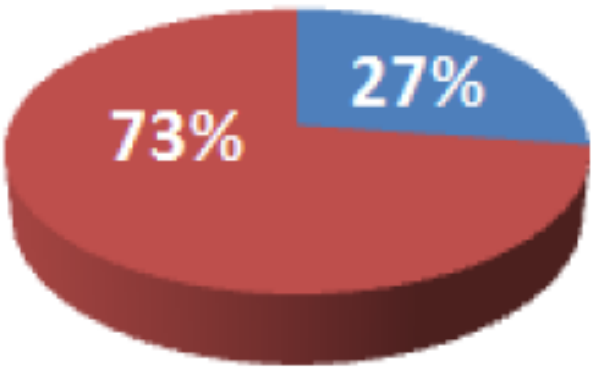

D. Frequency of Use
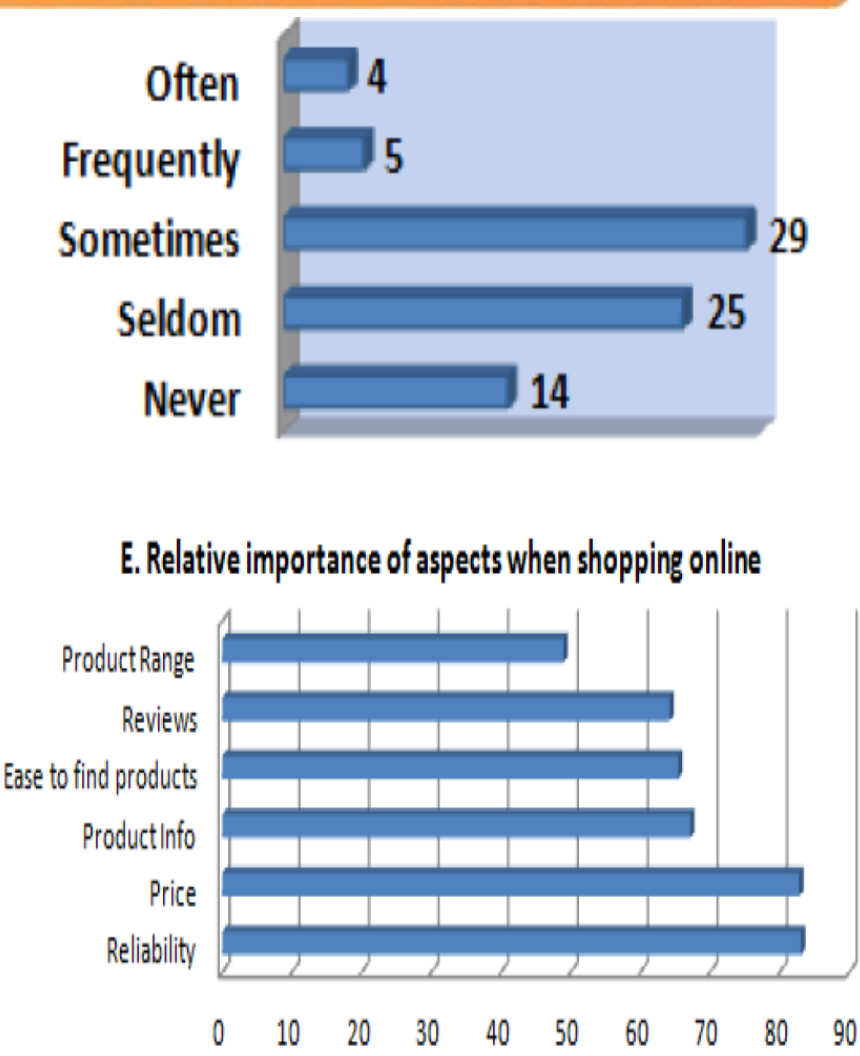

Fig. 2: Study Sample: Key Characteristics

Procedures for Statistics Exploration

Data analysis conventions comprising multivariate normality, multicollinearity, as well as correlations were initially checked. Variance - inflation factor (VIF) was computed as a way of checking for multicollinearity amid the forecast factors. Estimates of $\mathbf{5 . 0}$ and above shows the presence of multicollinearity issues within the forecast factors [37] while association concerning hypotheses were tested using Pearson's correlation analysis. A correlation coefficient $(r)$ estimate between 0.10 and 0.29 is assumed low, between 0.30 and 0.49 is taken as average, while between 0.50 and 1.0 is regarded high. To circumvent multicollinearity, $r$ must be within the range of 0.8 [38]. Exploratory factor analysis, as well as confirmatory factor analysis, were applied to examine hypotheses in the recommended framework for reliability, unidimensionality, and construct validity with both convergent validity and discriminant validity.

The removal condition for factor analysis is put at an eigenvalue that is above 1.0. Items having lesser factor loadings $(<0.50)$ are removed [39]. Unidimensionality, reliability, convergent validity, as well as discriminant validity, were examined to ensure framework consistency [40]. Multiple regression analysis was used in the study of the association concerning the 
dependent and independent variable(s) [41]. This statistical method was thus chosen as suitable in this instance to validate the proposed constructs. SPSS package was utilised in the evaluation of data analysis conventions, framework suitability tests, and multiple regression analysis.

\section{RESULTS AND DISCUSSION}

\section{A. Multiple Regression Models on Perceived} USABILITY

Table 2 shows the result of the full multiple regression model of perceived usability on the eight (8) independent variables, together with two control variables: impact of reviews and effects of price, in the presence of five (5) interaction variables namely: MaleSym, MaleCD , OwnFP_UseFP, Int_Sym and Int_CD, which respectively represent symmetry as perceived by male users, colour design as seen by males, ownership of food processor and willingness to use a food processor as viewed by male users, general interaction effects of symmetry and colour design.

TABLE 2

RESULT OF FULL MULTIPLE REGRESSION MODELS ON PU COEFFICIENTS $^{\mathbf{a}}$

\begin{tabular}{|l|r|r|r|r|}
\hline Full model *** & Unst.B & St.B & \multicolumn{1}{c|}{$t$} & \multicolumn{1}{c|}{ Sig. } \\
\hline (Constant) & 45.797 & 4.672 & 9.803 & $0.000^{*}$ \\
Screen Density & 2.841 & 0.861 & 3.298 & $0.001 *$ \\
Navig.Design & -0.073 & 0.861 & $0-.084$ & 0.933 \\
Symmetry & -2.211 & 1.247 & -1.773 & 0.076 \\
Colour Design & -4.761 & 1.247 & -3.818 & $0.000^{*}$ \\
Font Design & 0.488 & 0.861 & 0.567 & 0.571 \\
Professionalism & 1.058 & 0.861 & 1.228 & 0.220 \\
Product Rating & 3.854 & 0.861 & 4.474 & $0.000^{*}$ \\
Freq. buy online & 0.918 & 0.455 & 2.018 & $0.044^{* *}$ \\
Impct of Price & 0.099 & 0.042 & 2.355 & $0.019^{* *}$ \\
Impct of Reviews & 0.055 & 0.027 & 2.022 & $0.043^{* *}$ \\
Impct Reliability & -0.085 & 0.031 & -2.696 & $0.007 *$ \\
Impact Prd.Rng. & 0.153 & 0.029 & 5.240 & $0.000^{*}$ \\
Food Proc.Own. & 7.816 & 1.079 & 7.244 & $0.000^{*}$ \\
Int.in using a FP & 7.369 & 1.919 & 3.840 & $0.000^{*}$ \\
MaleSym & 0.061 & 1.767 & 0.034 & 0.973 \\
MaleCD & 3.101 & 1.767 & 1.755 & 0.080 \\
OwnFP_UseFP & -21.504 & 2.063 & -10.424 & $0.000^{*}$ \\
Int_Sym & 3.057 & 1.942 & 1.574 & 0.116 \\
Int_CD & -2.762 & 1.942 & -1.422 & 0.155 \\
\hline
\end{tabular}

a. Dependent Variable: Perceived Usability

$*=$ Statistically significant at $1 \%-$ level

$* *=$ Statistically significant at $5 \%-$ level

$* * *$

$R^{2}$ of model: 0.178, ANOVA: $F: 11.215->p=0.000^{*}$

A notable feature from the output of Table 2 is that noticeably more factors bear a substantial impact on perceived usability. 11 factors ( 3 screen variables, 7 control variables including 1 interaction variable) bear statistically substantial impact at a $5 \%$ threshold, while 8 of them likewise bear major impact at a $1 \%$ threshold. Similarly, the mediating factor MaleCD likewise bears a minimal notable impact on $P U$, with a $p$-level in the range of $10 \%$ threshold $(p=0.080)$.

B. Multiple Regression Models on Willingness To Use.

Table 3 shows the result of the full multiple regression model of willingness to use (WtU) on the eight (8) independent screen variables, together with two control variables: impact of reviews and impact of price, with the addition of four (4) mediating factors believed to bear a minimal notable impact on $\mathrm{WtU}$ : MaleCD, MaleOwnFP, $O W n F P-U s e F P$ and Int_CD.

TABLE 3: RESULT OF FULL MULTIPLE REGRESSION MODEL ON WtU COEFFICIENTS $^{\mathbf{a}}$

\begin{tabular}{|l|r|r|r|r|}
\hline Full model *** & \multicolumn{1}{|c|}{ Unst.B } & \multicolumn{1}{c|}{ St.B } & \multicolumn{1}{c|}{$t$} & \multicolumn{1}{|c|}{ Sig. } \\
\hline (Constant) & 50.881 & 5.327 & 9.552 & $0.000 *$ \\
Screen Density & 1.646 & 0.979 & 1.682 & 0.093 \\
Navig.Design & 0.756 & 0.979 & 0.773 & 0.440 \\
Symmetry & -1.315 & 0.979 & -1.344 & 0.179 \\
Colour Design & -4.447 & 1.414 & -3.145 & $0.002 *$ \\
Font Design & -0.344 & 0.979 & -0.352 & 0.725 \\
Professionalism & 0.627 & 0.979 & 0.640 & 0.522 \\
Product Rating & 4.276 & 0.979 & 4.369 & $0.000 *$ \\
Freq.buy online & 0.105 & 0.517 & -0.203 & 0.839 \\
Impact of Price & -0.116 & 0.048 & -2.391 & $0.017 * *$ \\
Impact of Reviews & 0.073 & 0.031 & 2.343 & $0.019 * *$ \\
Impct Reliability & -0.178 & 0.036 & -4.993 & $0.000 *$ \\
Impct Prd Rng & 0.142 & 0.034 & 4.183 & $0.000 *$ \\
Food Proc.Own & 16.798 & 1.522 & 11.038 & $0.000 *$ \\
Int.in using a FP & 17.295 & 1.894 & 9.132 & $0.000 *$ \\
MaleCD & 3.818 & 2.012 & 1.898 & 0.058 \\
MaleOwnFP & -19.058 & 2.187 & -8.715 & $0.000 *$ \\
OwnFP_UseFP & -17.197 & 2.350 & -7.317 & $0.000 *$ \\
Int_CD & -3.194 & 2.203 & -1.450 & 0.147 \\
\hline Dependent
\end{tabular}

a. Dependent Variable: Willingness to Use

* Statistically significant at $1 \%$ - level

** $=$ Statistically significant at $5 \%-$ level

$* * *$

$R^{2}$ of model: 0.221, ANOVA: $F: 15.588->p=0.000^{*}$

The following observations are noteworthy from Table 3 above: Among the 8 screen variables, 2 bear a major influence on WtU. 6 mediating factors likewise bear a substantial impact on WtU. Besides, the effect of Food Processor Ownership and Interest in using a food processor is very noticeable. The impact of MaleOWnFP interfacing factor is very substantial. Similarly, the other mediating factor, OWnFP_UseFP, likewise bears a convincing, notable influence on willingness to use. The factor, OWnFP_UseFP, denotes a situation where participants own a food processor and are further willing to use a food processor. In such an instance, participants rank the screens substantially less relative to the willingness to use. 


\section{Vol. [46], Issue [1], Year (2020)}

In comparison to Table 2 , it is evident that Table 3 clarifies a greater measure concerning the variations in the output factor (0.221 vs. 0.178).

\section{Examination of Constructs}

It is intended to determine the major effect of the 8 screen attributes, outlined in section 3.2.1, on perceived usability and willingness to use. Consequently, the results of Table 2 and Table 3 will be used to ascertain the veracity, or otherwise, of the constructs presented in section 2.3 .

\section{Classical Artistry (CA)}

$H_{1 a}$ : Interface designs with low screen density will lead to higher perceived usability

$H_{1 b}$ : Interface designs with low screen density will lead to a higher willingness to use

In the regression model, this implies for a significant negative Beta $(B)$, the null construct holds. From Table 2, it is seen that the impact of Screen Density on $P U$ was significant at a $1 \%$ threshold $(p=0.001)$. However, the Beta of the relationships is positive ( $B=2.841$ ), implying low screen density results in less perceived usability. Thus, $H_{1 a}$ is discarded. Regarding the impact of Screen Density on willingness to use, similar argument prevails, i.e., $(B=1.646)$. Moreover, the impact of Screen Density bears no substantial influence on $\mathrm{WtU}$, so $H_{1 b}$ is likewise discarded.

The next construct is similarly formulated thus:

$\mathrm{H}_{2 a}$ : Clear and simple navigation design positively affects perceived usability.

$H_{2 b}$ : Clear and simple navigation design positively

affects willingness to use

Validating the constructs of $H_{2 a}$ and $H_{2 b}$, the $B$ of navigation design must be negative and significant. Although this hold in Table 2, for $P U$, the impact is observed as being very trivial, $(p=.093)$. Thus, $H_{2 a}$ is rejected. Regarding WtU (Table 3), the effect of navigation design is substantially of higher consequence but distant from being statistically significant ( $p>0.4$ ). More so, the Beta in this model is non-negative contrary to a conjectured negative $B$. Therefore, $H_{2 b}$ is similarly rejected.

$H_{3 a}$ : Symmetry positively affects users' perceived usability

$H_{3 b}$ : Symmetry positively affects users' willingness to use

$\mathrm{H}_{3 c}$ : Artistic perceptions of males on symmetry are

significantly different from females

For the null construct to be accepted, the Beta for Symmetry is assumed positive and significant for $P U$ and $W t U$. From Table 2 and Table 3, it is noted that the observed Beta is in contrast to the expected. Though, in Table 2, the impact of symmetry is asymptotically significant at a $5 \%$ threshold ( $p=0.076)$. For the last construct, the interaction factor MaleSym was calculated to ascertain its impact. Unfortunately, its $p$-value was very trivial (0.973). In addition to previous discoveries on symmetry, the proposed constructs were notably rejected.

Communicative $\operatorname{Artistry}(\mathrm{EA})$

Colour Design, Font Design, as well as

Professionalism, constitute the factors under consideration.

$H_{4 a}$ : The use of extreme short-wavelength colours positively influences perceived usability

$H_{4 b}$ : The use of extreme short-wavelength colours positively influences the willingness to use

Beta is assumed positive and statistically relevant at $1 \%$ $p$-level for the proposed null construct to be in the affirmative. Though in the regression models of Table 2 and Table 3, the Beta for colour design is negative and statistically relevant at $1 \%$ threshold; unfortunately so, it is contrary to conjecture. Consequently, $H_{4 a}$ and $H_{4 b}$ are rejected.

Regarding Font Design, the proposed constructs are:

$H_{5 a}$ : Variety in font design positively affects perceived usability

$H_{5 b}$ : Variety in font design positively affects willingness to use The proposed constructs $H_{5 a}$ and $H_{5 b}$ are in the affirmative if the Beta for font design is non-negative and significant. From Table 2, the Beta for Font Design is indeed positive though, the impact is trivial, having a $p$-value greater than 0.3 . For the regression model of $\mathrm{WtU}$ (Table 3 ), the impact of font design is relatively very inconsequential $(p-$ value $>0.7)$. Since the computed Beta is in contrast to the expected the proposed constructs $H_{5 a}$ and $H_{5 b}$ are rejected.

Another factor related to communicative artistry is

Professionalism. The proposed constructs, in this case, are:

$H_{6 a}$ : Professional appearance negatively affects perceived usefulness

$H_{6 b}$ : Professional appearance positively affects willingness to use

For $H_{6 a}$ to be valid, the computed Beta is assumed nonpositive as well as noteworthy, while for $H_{6 b}$ it is considered non-negative and statistically relevant. From Table 2, the Beta is positive, and the impact turned out as trivial, having a $p$-value of 0.220. For the impact on $\mathrm{WtU}$ (Table 3) Beta is non-negative as conjectured. Nevertheless, the impact is insignificant, having a $p-$ value $>0.5$, thereby leading to the rejection of $6_{6 a}$ and $H_{6 b}$.

\section{Impact of Perceived Usability on Willingness to Use}

In addition to the proposed constructs, it was similarly conjectured that the related factor perceived usability bears a major impact on a similar related factor, willingness to use, thus inducing the seventh construct: 
$H_{7}$ : Perceived usability positively influences the willingness to use

Since Tables 2 and 3 concentrate on examining correlations amid the independent and dependent factors, the impact of $\boldsymbol{P U}$ on $\mathbf{W t U}$ is still to be tested. As a way of exploring this association, another regression model is constructed having the willingness to use as a dependent factor and perceived usability as a forecasting factor. Table 4 shows the result of the model.

TABLE 4: RESULT OF REGRESSION MODEL ON PU vS WtU COEFFICIENTS ${ }^{\text {a }}$

\begin{tabular}{|c|c|c|c|c|c|}
\hline \multirow[t]{2}{*}{ Model $* *$} & \multicolumn{2}{|c|}{ Unstd.Coeff } & \multirow{2}{*}{$\begin{array}{c}\text { Std.Coeff } \\
\text { Beta }\end{array}$} & \multirow[t]{2}{*}{$t$} & \multirow[t]{2}{*}{ Sig } \\
\hline & $B$ & Std.Err & & & \\
\hline (Const) & 9.536 & 1.709 & & 5.579 & $.000 *$ \\
\hline $1 \quad P U$ & .682 & .028 & .604 & 25.586 & $.000 *$ \\
\hline
\end{tabular}

a. Dependent Variable: Willingness to use

1) $*=$ statistically significant at $1 \%$ - level

2) $R^{2}$ of Model: 0.365, ANOVA: $F: 706.806->p=0.000^{*}$

From this output, there are a few things that are worthy of note. First, the impact of perceived usability on willingness to use is very substantial at a $1 \%$ threshold. Computed $t$-value is also extraordinarily huge. Second, computed $R^{2}$ for the regression model stood at 0.365 , suggesting that perceived usability accounts for $36.5 \%$ of the divergence in willingness to use. Results from Table 4 suggests that incorporating $P U$ as the only forecast factor in a regression model clarifies to a greater extent the divergence in $\mathrm{WtU}$ compared to a regression model of Table 2, having 0.221 as its $R^{2}$. One other fact deducible from Table 4 concerns the impact of $P U$ on $\mathrm{WtU}$, which is non-negative, given the Beta (0.682) for perceived usability. Thus, the seventh construct is accepted. Table 5 shows a summary of the constructs evaluation.

TABLE 5: SUMMARY OF CONSTRUCTS EVALUATION

\begin{tabular}{|c|c|c|c|}
\hline Construct & Result $^{\mathrm{a}}$ & Result $^{\mathbf{b}}$ & $\mathrm{H}_{0}{ }^{\mathrm{c}}$ \\
\hline 1a: Scrn Density $->P U$ & $(-)$ & $(+) *$ & Rejected \\
\hline $1 b:$ Scrn Density $\rightarrow W t U$ & $(-)$ & $(+) * *$ & Rejected \\
\hline $2 a$ : Navig. Design $\rightarrow P U$ & $(-)$ & $(-)$ & Rejected \\
\hline $2 b:$ Navig. Design $->W t U$ & $(-)$ & $(+)$ & Rejected \\
\hline 3a: Symmetry $->P U$ & $(+)$ & $(-) * *$ & Rejected \\
\hline $3 b:$ Symmetry $\rightarrow$ WtU & $(+)$ & $(-)$ & Rejected \\
\hline $4 a:$ Color Design $->P U$ & $(+)$ & $(-) *$ & Rejected \\
\hline $4 b:$ Color Design $\rightarrow W t U$ & $(+)$ & $(-) *$ & Rejected \\
\hline $5 a:$ Font Design $\rightarrow P U$ & $(+)$ & $(+)$ & Rejected \\
\hline
\end{tabular}

${ }^{a}$ Expected

b Observed

${ }^{\mathrm{c}}$ Accepted/Rejected

\begin{tabular}{|l|ccl|}
\hline Construct & Result $^{\mathbf{a}}$ & Result $^{\mathbf{b}}$ & $\boldsymbol{H}_{0} \mathbf{c}$ \\
\hline 5b: Font Design $->W t U$ & $(+)$ & $(-)$ & Rejected \\
6a: Prof_nalism $\rightarrow P U$ & $(-)$ & $(+)$ & Rejected \\
6b: Prof_nalism $\rightarrow$ WtU & $(+)$ & $(+)$ & Rejected \\
7: PU $\rightarrow$ WtU & $(+)$ & $(+) *$ & Accepted \\
\hline
\end{tabular}

D Discussion

The impact on willingness to use, concerning navigation design, is negative while its effect on perceived usability is positive. This outcome is due to the framing effect discovered in previous works, where clients' inclinations changed in response to job execution [15; $16 ; 22]$ since practically using a screen-based artefact is presumably somewhat akin to a job than ranking the usability of a portable display. Nevertheless, given the trivial impacts recorded, the presence of such an impact must be investigated in further works.

In contrast to Navigation Design, Screen Density very fundamentally impacted $P U$ as well as $\mathrm{WtU}$. The impact in the two instances although happen to be non-negative, even though a non-positive influence was conjectured. This discovery is not yet reported in previous works. Whereas the impact of Symmetry on $P U$ was seen as slightly substantial at a $10 \%$ threshold, the impact concerning $P U$ and $\mathrm{WtU}$ was trivial at a $5 \%$ threshold. At any rate, as a consequence of the outcomes, it is likely symmetry may bear a very marginal impact on perceived usability as well as willingness to use.

Results affirmed that Color Design fundamentally impacted $P U$ and $\mathrm{WtU}$, even though the orientation of the impact differs from the conjecture. The variation may be accounted for via Hofstede's scale of individualism, where, for instance, the Netherlands get $\mathbf{8 0}$, measured as being impressively remarkable. This assumption agrees with the remarks of [24] in which clients of communist origin are inclined to intense graphics, in contrast to clients of capitalist nations, like the Netherlands, who are inclined to a consistent and organised page layout. Conversely to Colour Design, the remaining EA attributes are remarkably very trivial, indicating an insignificant impact on perceived usability or willingness to use, even though Professionalism appeared to bear a very marginal impact on $P U$.

The last construct examined is the impact of $P U$ on $\mathrm{WtU}$, which turned out as being very substantial as confirmed by Table 4. Consequently, one may surmise that the two related factors, $P U$ and $\mathrm{WtU}$, are strongly associated. Thus, an increase in perceived usability of the architecture of a portable display manifests in higher willingness to use applications on such platforms. This result agrees with the conjectured impact. 


\section{CONCLUSION}

This work does a joint evaluation of the different factors to show the impact of individual factors, as a way of creating an artistically-optimal customer display, as well as proffer suggestions regarding such enhancements. This observation s a missing link in empirical studies on m-commerce that this work filled and hence, its novelty. Standards in the artistic architecture of a portable display may be the starting point in achieving general as well as reliable procedures for portable gadgets architects which will consider all aspect of client display architecture.

It is intriguing to note that not a single one of the conjectured impacts related to both classical and communicative artistry, proposed and investigated holds. Can it then be surmised that artistic architecture bears no substantial effect on perceived usability of portable websites as well as the willingness to use programs on such platforms? Given the non-existence of significant impacts, such deduction will be accurate. Though, while not a single one of the artistry-based conjectures hold, computed outputs reflect substantial impacts. That the orientation of some of the effects is a reverse of the conjectured outcome is not suggestive that investigated factors bear no effect on $P U$ and $\mathrm{WtU}$. Screen density, as well as the colour design of a program, turned out as two features with the highest impact. Also, the symmetry of wares arranged on a portable display similarly influenced the perceived usability of a program. In the light of these discoveries, the simple summary is artistic architecture bears a substantial impact on perceived usability of portable websites and programs as well as influences willingness to use artefacts on such platforms.

\section{A. Implications of Findings}

The investigation revealed that artistic architecture impacts more positively on perceived usability of an mcommerce program or website and consequently boost the client's willingness to use. This outcome may have a corresponding definite escalation in the adoption rates with a resultant increase in the revenue accruing to the company. Evidence from the study similarly supports the variability in the influence of some display attributes in different circumstances. As an instance, overall, a common likeness was noted for neutral colour artistry. Meanwhile, additional examination of this effect revealed dissimilarity in gender preferences for artistic shades. Thus, there is a need to segment the clientele; understanding the different choices of the client is crucial in the architecture of a portable website or program.

\section{B. Limitation of Study and Further Research}

The online survey conducted for the investigation is noted as a limitation since it resulted in measuring only the subjective responses of respondents. Likewise, the demography of sample participants consists of low-income literates within the 18-25 age range and thus forecloses generalisation across the population strata. Conducting a more reflective investigation involving the different strata of the population is, therefore, recommended. This assists in gaining accurate knowledge regarding the dynamics of portable display sites and programs and its attendant impact on the artistic architecture on perceived usability and willingness to use. Furthermore, the approach used in this research is quantitative, which is considered inadequate in eliciting the latent causes for the observed outcome. Thus, research in this area may consider a qualitative research approach to gain more insight into the causative details concerning the association revealed in the quantitative approach,

\section{REFERENCES}

[1] H. R. Marriott, M. D. Williams, and Y. Dwivedi, "What do we know about consumer m-shopping behaviour?', International Journal of Retail \& Distribution Management, Vol. 45, No 6, pp.568-586. 2017.

https://doi:10.1108/ijrdm-09-2016-0164.

[2] Statista, "Number of smartphone users worldwide from 2009 to 2019 (in millions)", March 302020 Retrieved from

http://www.statista.com/statistics/271596/number-of-smartphone-usersworldwide/

[3] EcommerceNews., 'Top 500 European e-retailers generated sales of $€ 124$ billion". April 29 2019, Retrieved from http://ecommercenews.eu/top500-european-e-retailers-generated-sales-of-e124-billion/

[4] R. Criteo, "State of Mobile Commerce. Growing like a weed", Q1 2015

[5] N. McCarthy, "Reasons for Shopping on a Computer vs. Mobile Device", $\begin{array}{lllll}\text { June } & 25 & 2014 . & \text { Retrieved }\end{array}$ https://www.statista.com/chart/2392/reasons-for-shopping-on-acomputer-vs-mobile-device/

[6] V. Shankar and S. Balasubramanian, 'Mobile Marketing: A Synthesis and Prognosis", Journal of Interactive Marketing, Vol. 23, pp. 118-129, 2009.

[7] V. Shankar, A. Venkatesh., C. Hofacker and P. Naik, "Mobile marketing in the retailing environment: current insights and future research avenues", Journal of interactive marketing, Vol. 24, No 2, pp.111-120, 2010.

[8] E. Swilley, Mobile commerce: How it contrasts, challenges, and enhances electronic commerce, New York, NY: Business Expert Press, 2015.

[9] T. Chi, "Mobile Commerce Website Success: Antecedents of Consumer Satisfaction and Purchase Intention", Journal of Internet Commerce, 2018. https://doi.org/10.1080/15332861.2018.1451970

[10] A. Ahmad and M. N. Khan, "Developing a website service quality scale: A confirmatory factor analytic approach", Journal of Internet Commerce, Vol. 16, No 1, pp.104-26, 2017.

https://doi.org/10.1080/15332861.2017.1283927

[11] TW. Andreassen et al., "Linking service design to value creation and service research", Journal of Service Management, Vol. 27, No 1, pp. 2129, 2016. https://doi.org/10.1108/josm-04-2015-0123 


\section{Vol. [46], Issue [1], Year (2020)}

[12] N. Ashraf, C.M. Faisal, S. Jabbar, and M.A. Habib, "The Role of Website Design Artefacts on Consumer Attitude and Behavioral Intentions in Online Shopping". Technical Journal, University of Engineering and Technology, Vol. 24, No 2, pp. 50-60, 2019.

[13] R.F. Bertram and T. Chi, "A study of companies' business responses to fashion ecommerce's environmental impact", International Journal of Fashion Design, Technology and Education, Vol. 11, No 2, pp.:254-264, 2018.

[14] D. Cyr, M. Head and A. Ivanov, "Design aesthetics leading to m-loyalty in mobile commerce", Journal of Information \& Management, Vol. 43, No 8, pp. 950-963, 2006.

https://doi.org/10.1080/17543266.2017.1406541.

[15] J. Hartmann, A. Sutcliffe and A. De Angeli, "Investigating attractiveness in web user interfaces", Proceedings of the SIGCHI conference on Human factors in computing systems, New York, ACM, pp. 387-396, 2007.

[16] J. Hartmann, A. Sutcliffe and A. De Angeli, "Towards a theory of user judgment of aesthetics and user interface quality", ACM Transactions on Computer-Human Interaction (TOCHI), Vol. 15 No 4, p. 15, 2008.

[17] J. Sauer and A. Sonderegger, "The influence of prototype fidelity and aesthetics of design in usability tests: Effects on user behaviour, subjective evaluation and emotion", Applied ergonomics, Vol. 40 No 4, pp. 670-677, 2009.

[18] A. Sonderegger and J. Sauer, "The influence of design aesthetics in usability testing: Effects on user performance and perceived usability", Applied ergonomics, Vol. 41 No 3, pp. 403-410, 2010.

[19] M. Bauerly and Y. Liu, "Computational modelling and experimental investigation of effects of compositional elements on interface and design aesthetics", International Journal of Human-Computer Studies, Vol. 64 No 8, pp. 670-682, 2006.

[20] A.N. Tuch, J.A. Bargas-Avila, and K. Opwis, "Symmetry and aesthetics in website design: It's a man's business", Computers in Human Behavior, Vol. 26, No 6, pp. 1831-1837, 2010.

[21] YM Li, and Y.S. Yeh, "Increasing trust in mobile commerce through design aesthetics". Computers in Human Behaviour", Vol. 26, No 4, pp. 673-684, 2010

[22] P. van Schaik and J. Ling, "The role of context in perceptions of the aesthetics of web pages over time", International Journal of HumanComputer Studies, Vol. 67, No 1, pp. 79-89, 2009.

[23] P. Nanda, J. Bos, K.L. Kramer, C. Hay and J. Ignacz, "Effect of smartphone aesthetic design on users' emotional reaction: An empirical study", The TQM Journal, Vol. 20, No 4, pp. 348-355, 2008.

[24] J. Hasanov and H. Khalid, "The impact of website quality on online purchase intention of organic food in Malaysia: A WebQual model approach", Procedia Computer Science Vol. 72, pp. 382-389, 2015.

https://doi.org/10.1016/j.procs.2015.12.153.

[25] SW. Wang, W. Ngamsiriudom, and C. H. Hsieh, "Trust disposition, trust antecedents, trust, and behavioural intention", The Service Industries Journal Vol. 35, No 10, pp. 555-572, 2015.

https://doi.org/10.1080/02642069.2015.1047827

[26] B. Kahn, "Using visual design to improve customer perceptions of online assortments", Journal of Retailing, Vol. 93, No 1, pp. 29-42, 2017.

[27] T. Lavie and N. Tractinsky, "Assessing dimensions of perceived visual aesthetics of web sites", International journal of human-computer studies, Vol. 60, No 3, pp. 269-298, 2004.

[28] M. Moshagen and M.T. Thielsch, "Facets of visual aesthetics", International Journal of Human-Computer Studies, Vol. 68, No 10, pp. 689-709, 2010.

[29] J. Smith, "The Jaw Dropping Effect that Images Can Have on your Conversion Rates", January 29 2014. Retrieved from

https://www.jeremysaid.com/blog/the-jaw-dropping-effect-that-images-canhave-on-your-conversion-rates

[30] D.M. Koo and S.H. Ju, "The interactional effects of atmospherics and perceptual curiosity on emotions and -online shopping intention", Computers in Human Behaviour, Vol. 26, No 3, pp. 377-388, 2010.

[31] A. Bigoin-Gagnan and S. Lacoste-Badie, "Symmetry influences packaging aesthetic evaluation and purchase intention", International
Journal of Retail \& Distribution Management, Vol. 46 No. 11/12, pp. 1026-1040, 2018. https://doi.org/10.1108/IJRDM-06-2017-0123

[32] A. Bilgihan, J. Kandampully and T. Zhang, "Towards a unified customer experience in online shopping environments: Antecedents", International Journal of Quality and Service Sciences, Vol. 8 No 1, pp. 102-119, 2016. https://doi.org/10.1108/ijqss-07-2015-0054.

[33] K.E. Schmidt, Y. Liu and S. Sridharan, "Webpage aesthetics, performance and usability: Design variables and their effects", Ergonomics, Vol. 52, No 6, pp. 631-643, 2009.

[34] L. Bergkvist and J.R. Rossiter, "The predictive validity of multiple-item versus single-item measures of the same constructs", Journal of marketing research, Vol. 44, No 2, pp. 175-184, 2007.

[35] B. J. Mariadoss, , T. Chi, P. Tansuhaj, and N. Pomirleanu, "Influences of firm orientations on sustainable supply chain management", Journal of Business Research, Vol. 69, No 9, pp/ 3406-3414, 2016 https://doi:10.1016/j.jbusres.2016.02.003.

[36] T. Chi, and Y. Sun, "Development of firm export market oriented behavior: Evidence from an emerging economy". International Journal of Business Review, Vol. 22, No 1, pp. 339-50, 2013.

https://doi:10.1016/ jbusrev.2012.05.003.

[37] L. Ott, M. Longnecker, and R. L. Ott, "An introduction to statistical methods and data analysis. Grove, CA: Duxbury Pacific, 2001.

[38] A. Field, "Discovering statistics using SPSS", Thousand Oaks, CA: Sage Publications, 2009

[39] B. Yoo, and N. Donthu, "Developing and validating a multidimensional consumer-based Brand equity scale", Journal of Business Research Vol. 52, No.1, pp. 1-14, 2001 doi:10.1016/s0148- 2963(99)00098-.

[40] J. Nunnally, and I. Bernstein, "Psychometric theory", New York, NY: McGraw-Hill, 1978.

[41] J. Cohen, and P. Cohen, 1975 "Applied multiple regression/correlation analysis for the behavioral sciences", Hillsdale, NJ: Lawrence Erlbaum, 1975. 